Journal for ImmunoTherapy of Cancer

\title{
Neospora caninum: a new class of biopharmaceuticals in the therapeutic arsenal against cancer
}

\author{
Louis Lantier (D) , ${ }^{1}$ Agathe Poupée-Beaugé, ${ }^{1}$ Anne di Tommaso, ${ }^{1}$ \\ Céline Ducournau, ${ }^{1}$ Mathieu Epardaud, ${ }^{2}$ Zineb Lakhrif, ${ }^{1}$ Stéphanie Germon, ${ }^{1}$ \\ Françoise Debierre-Grockiego, ${ }^{1}$ Marie-Noëlle Mévélec, ${ }^{2}$ Arthur Battistoni, ${ }^{1}$ \\ Loïs Coënon, ${ }^{1}$ Nora Deluce-Kakwata-Nkor, ${ }^{3}$ Florence Velge-Roussel, ${ }^{3}$ \\ Céline Beauvillain, ${ }^{4}$ Thomas Baranek, ${ }^{5}$ Gordon Scott Lee, ${ }^{6}$ Thibault Kervarrec, ${ }^{1,7}$ \\ Antoine Touzé, ${ }^{1}$ Nathalie Moiré, ${ }^{2}$ Isabelle Dimier-Poisson ${ }^{1}$
}

To cite: Lantier L, PoupéeBeaugé A, di Tommaso A, et al. Neospora caninum: a new class of biopharmaceuticals in the therapeutic arsenal against cancer. Journal for ImmunoTherapy of Cancer 2020;8:e001242. doi:10.1136/ jitc-2020-001242

- Additional material is published online only. To view, please visit the journal online (http://dx.doi.org/10.1136/jitc2020-001242).

$\mathrm{LL}$ and $\mathrm{AP}-\mathrm{B}$ are joint first authors.

Accepted 02 0ctober 2020

Check for updates

(C) Author(s) (or their employer(s)) 2020. Re-use permitted under CC BY-NC. No commercial re-use. See rights and permissions. Published by BMJ.

For numbered affiliations see end of article.

Correspondence to

Dr Louis Lantier;

louis.lantier@univ-tours.fr

\section{ABSTRACT}

Background Microorganisms that can be used for their Iytic activity against tumor cells as well as inducing or reactivating antitumor immune responses are a relevant part of the available immunotherapy strategies. Viruses, bacteria and even protozoa have been largely explored with success as effective human antitumor agents. To date, only one oncolytic virus - T-VEC — has been approved by the US Food and Drug Administration for use in biological cancer therapy in clinical trials. The goal of our study is to evaluate the potential of a livestock pathogen, the protozoan Neospora caninum, non-pathogenic in humans, as an effective and safe antitumorous agent.

Methods/Results We demonstrated that the treatment of murine thymoma EG7 by subcutaneous injection of $N$. caninum tachyzoites either in or remotely from the tumor strongly inhibits tumor development, and often causes their complete eradication. Analysis of immune responses showed that $N$. caninum had the ability to 1 ) lyze infected cancer cells, 2) reactivate the immunosuppressed immune cells and 3) activate the systemic immune system by generating a protective antitumor response dependent on natural killer cells, CD8-T cells and associated with a strong interferon (IFN)- $\gamma$ secretion in the tumor microenvironment. Most importantly, we observed a total clearance of the injected agent in the treated animals: $N$. caninum exhibited strong anticancer effects without persisting in the organism of treated mice. We also established in vitro and an in vivo non-obese diabetic/ severe combined immunodeficiency mouse model that $N$. caninum infected and induced a strong regression of human Merkel cell carcinoma. Finally, we engineered a N. caninum strain to secrete human interleukin (IL)-15, associated with the alpha-subunit of the IL-15 receptor thus strengthening the immuno-stimulatory properties of N. caninum. Indeed, this NC1-IL15hRec strain induced both proliferation of and IFN- $\gamma$ secretion by human peripheral blood mononuclear cells, as well as improved efficacy in vivo in the $E G 7$ tumor model.

Conclusion These results highlight $N$. caninum as a potential, extremely effective and non-toxic anticancer agent, capable of being engineered to either express at its surface or to secrete biodrugs. Our work has identified the broad clinical possibilities of using $N$. caninum as an oncolytic protozoan in human medicine.

\section{BACKGROUND}

As of 2011 immunotherapy, which educates the immune system to effectively fight cancer cells, has been added to the arsenal of conventional cancer therapies. Several avenues have been explored such as immune checkpoint blockade ${ }^{1}$ and CAR-T ${ }^{2}{ }^{3}$ therapies and, for a minority of specific cases, significant improvement in survival outcomes have resulted. Live microorganisms also represent a promising therapeutic approach due to their lytic activity on tumor cells and/or their ability to stimulate the immune system, especially via target molecules of innate immunity. Attenuated viruses and bacteria have been largely explored as vaccine vectors to elicit T-cellmediated immunity and to induce protective response against tumor development. ${ }^{4-6}$ Moreover, those microorganisms can be genetically modified to further express molecules that potentiate immune responses and/or target tumor antigens. Thus, the approval of the first virotherapy was based on the use of a herpes simplex virus (HSV) expressing granulocyte-macrophage colonystimulating factor (GM-CSF) and genetically modified to preferentially target tumor cells for the treatment of metastatic melanomas has attracted tremendous attention in the field of cancer therapy. ${ }^{7}$ More recently, therapeutic approaches using live, tumor-targeting bacteria (Salmonella, Listeria, Clostridium, Bifidobacterium and so on) have emerged as promising cancer treatment strategies. ${ }^{8}$ Also used as vectors for delivering or expressing tumor suppressor genes or tumor-associated antigens, bacteria have showed promising 
antitumor activity in various preclinical tumor models. ${ }^{9}$ Among other microorganisms, intracellular protozoa have been identified as a new avenue of exploration. In 2011, Junqueira et al demonstrated that Trypanosoma cruzi was highly efficient in inducing T-cell-mediated immunity and protection against melanoma. ${ }^{10}$ The immunostimulatory properties of Toxoplasma gondii have also been known for many years. Indeed, chronic infection and even parasite extracts have conferred resistance and cross protection in the mouse to many pathogens including viruses, ${ }^{11}$ bacteria, ${ }^{12}$ parasites, ${ }^{13}$ yeast ${ }^{14}$ and even mammary tumors. ${ }^{15}$ Recently, new studies have confirmed the interest of using T. gondii in antitumor immunotherapy. Those studies used live, non-replicating Toxoplasma, named CPS (for disruption of the Carbamoyl Phosphate Synthetase gene). ${ }^{16}$ Tumor regressions were observed in the case of murine melanoma (B16F10), ovarian cancer (ID8) and pancreatic cancer (Pan02) following intratumorous injections of CPS. ${ }^{17-19}$ In any case, the living protozoan, by activating the innate immune system, reverses the immunosuppresion and leads to the reactivation of a specific immune response against the tumor.

However, those pathogens can persist for a long time in human bodies and in some cases, if not treated, can induce severe diseases. Thus, it seems appropriate to determine if the use of a naturally occurring protozoan, non-infectious for humans, can be a relevant therapeutic agent. To explore this opportunity, we focused on the livestock pathogen Neospora caninum, an intracellular protozoa closely related to $T$. gondii, identified in 1984 by Bjerkås $e t a l .^{20}$ Little is known about the epidemiology of $N$. caninum infection in humans. While the few available sero-epidemiological studies demonstrated very low seropositivity rates in T. gondii-seropositive individuals, ${ }^{21}$ blood donors ${ }^{22}$ HIV-infected patients or patients with neurological disorders, ${ }^{23} \mathrm{~N}$. caninum has not been demonstrated in human tissues and there is no evidence that neosporosis is a zoonosis.

As in humans, very low frequency of seropositivity with $N$. caninum was detected in the Mus domesticus population $(3 \%) .{ }^{24}$ However, several mouse models have been developed as an attempt to study $N$. caninum infection suggesting that a non-natural host can be infected by the protozoa. Furthermore, those data raise the question if $N$. caninum has infectious potential for human cells even if humans are resistant to the disease-which could thus be a safe microbial anticancer therapy.

We here report that treatment of EG7 thymoma in syngeneic mice by live $N$. caninum administered by remote (subcutaneous) or local (intratumor) injection can successfully inhibit both early and established tumor development. However, killed microbes were unable to mediate regression of tumors suggesting that the infectious nature of $N$. caninum was a required feature for successful protection.

The analysis of the immune responses and interactions between $N$. caninum and tumor cells allowed us to highlight that Neospora has the capacity to 1) directly destroy the cancer cells that it infects, 2) reactivate the local suppressed immune cells at the site of the tumor, 3) activate the systemic immune system by promoting the recruitment of immune cells to the site of the tumor leading to the establishment of a long-term antitumor response and, finally, 4) be reduced to undetectable levels suggesting the absence of persistence of $N$. caninum in tissues. We believe that our data merit further studies to support the possible application of N. caninum as a new, valuable immunotherapeutic agent for human cancer, a belief further reinforced by results obtained with human Merkel cell carcinoma and with engineered Neospora to express the human complex of interleukin (IL)-15 and the Sushi domain of $I L-15$ receptor a chain to improve effector response.

\section{MATERIALS AND METHODS \\ Mice}

Female C57BL/6 and non-obese diabetic/severe combined immunodeficiency (NOD/SCID) mice aged 8 weeks were purchased from CER Janvier (Le Genest Saint Isle, France) and maintained under pathogen-free conditions in the animal facility of the University of Tours.

\section{Parasites}

$N$. caninum (NC1 strain) and T. gondii (RH strain) tachyzoites were grown as described previously. ${ }^{25}$ For mouse injections, tachyzoites were collected by centrifugation at $600 \mathrm{~g}$ for $10 \mathrm{~min}$ and washed in phosphatebuffered saline (PBS). Heat-killed tachyzoites were obtained by heating freshly isolated tachyzoites $30 \mathrm{~min}$ at $60^{\circ} \mathrm{C}$.

The $N$. caninum total antigenic extract (TE) was prepared following the protocol described for T. gondii antigenic extract. ${ }^{26}$

\section{Tumor cell}

The murine thymoma cell line EG7 (EL4-OVA: EL-4 thymoma cells transfected with chicken albumin cDNA) was obtained from ATCC (CRL-2113). Tumor cells were cultured in RPMI (Pan Biotech) with 10\% of fetal calf serum (FCS) (Dutscher), $0.05 \mathrm{mM}$ of 2-mercaptoethanol (Pan Biotech), $50 \mathrm{IU} / \mathrm{mL}$ of penicillin/streptomycin (Pan Biotech) and $0.4 \mathrm{mg} / \mathrm{mL}$ geneticin (G418, Pan Biotech). The WaGa (RRID:CVCL_E998) cell line was used for Merkel cell carcinoma (MCC) studies, and was cultured in RPMI containing $10 \%$ FCS, $100 \mathrm{U} / \mathrm{mL}$ penicillin, streptomycin and amphotericin B.

\section{Experimental procedures and sample collection}

EG7 $\left(5 \times 10^{5}\right)$ or WaGa $\left(10^{7}\right)$, associated with $10 \%$ Matrigel $(10 \mathrm{mg} / \mathrm{mL}$, Corning) cells were subcutaneously inoculated in the flank of mice. Mice were then injected intratumorally or subcutaneously in the opposite flank with isolated tachyzoites in PBS, at the doses and times indicated in the figures. 
Tumor volume was determined as $\varpi / 6 \times$ width $\times$ length $\times$ height. Blood sera were collected via cheek bleeds from animals at the indicated time points.

Spleens and lymph nodes were mechanically disrupted, to obtain cell suspensions. The cells were then either plated in RPMI (5\% FCS, 2\% Hepes, $1 \%$ glutamine, $1 \%$ sodium-pyruvate, $50 \mathrm{~mL} / \mathrm{mL} \beta$-mercapto-ethanol, $100 \mathrm{U} /$ $\mathrm{mL}$ penicillin and streptomycin) for in vitro restimulation or resuspended in PBS-1\% BSA-0.2mM EDTA for flow cytometry analysis.

Tumors were harvested, weighed and measured after dissection. A first sample was collected and stored at $-80^{\circ} \mathrm{C}$ for further quantitative PCR (qPCR) analysis. Other samples were collected respectively in $4 \%$ formol or $4 \%$ paraformaldehyde for histological analysis and immunofluorescence on frozen section, respectively. The rest of the tumor was dissociated using the Tumor Dissociation Kit, mouse (Miltenyi Biotech) and gentleMACS Dissociator (Miltenyi Biotech). Cells were resuspended (PBS, $2 \mathrm{mM}$ EDTA, 1\% fetal bovine serum) for staining and flow cytometry analysis.

\section{Cell depletion}

Ultra-LEAF purified antimouse CD4 (GK1.5), antimouse CD8 (53-6.7), antimouse NK1.1 (PK136), antimouse Ly-6G (1A8) from BioLegend and clodronate liposomes from Liposoma were used for cells depletion. Ultra-LEAF purified Rat IgG2a, Rat IgG2b, mouse IgG2a isotype control antibodies from BioLegend, control liposomes from Liposoma and PBS were used like controls. Antibody $(30 \mu \mathrm{g})$, liposomes $(50 \mu \mathrm{L})$ or PBS were injected intratumorally 1 day after $N$. caninum treatment and then every 2-3 days until the sacrifice of mice.

\section{Cellular analysis and flow cytometry}

Antibody reagents were obtained from Miltenyi Biotech: REA clones of antimouse CD3-APC-Vio770 (REA606), CD4-Vioblue (REA 604), CD8a-PE-Vio770 (REA 601), Foxp3-Vio515 (REA 788), NKp46-APC (REA 815), CD11c-PE (REA 754), CD11b-APC-Vio770 (REA 592), Ly6C-Vioblue (REA 796), Ly6G-PE-Vio770 (REA 526). Foxp3 staining was performed using Foxp3 Staining Buffer Set (Miltenyi Biotech).

Flow cytometry analysis was performed using a Miltenyi 8-color MACSQuant, and data were analyzed using Flowlogic (Miltenyi Biotech).

\section{Cytokine detection}

Cytokine production in splenocyte culture supernatants and/or tumor dissociation supernatants were evaluated by ELISA with specific kits: IL-1 $\beta$, IL-6, IL-12p40, IL-18 and transforming growth factor (TGF) $-\beta$ (eBioscience), CCL2 and VEGF (Invitrogen), IL-15 and PDL1 (R\&D systems). For GM-CSF, interferon (IFN)- $\gamma$, IL-2, IL-4, IL-5, IL-10, IL-12p70, IL-17A, IL-23 and tumor necrosis factor (TNF)- $\alpha$, MACSPlex cytokine 10 kit (Miltenyi Biotec) was used according to the manufacturer's instructions.

\section{Statistical analysis}

All experiments were repeated at least two times with similar results between experiments. Statistical analysis was performed using GraphPad Prism software. P values $<0.05$ were considered to be statistically significant. Error bars show the SEM. Bar graphs were analyzed by one-way analysis of variance and scatter plots of tumor volume and weight were compared using Kruskal-Wallis nonparametric test.

More method details are provided in the online supplementary material and methods file.

\section{RESULTS \\ N. caninum live tachyzoites induce the production of proinflammatory cytokines by mouse and human immune cells}

Since humans are not natural hosts of N. caninum and the cross-talk between the protozoa and human innate immune cells has not yet been shown, it is important to study in vitro the relationship between Neospora and such cells in terms of infection and activation. Furthermore, those interactions should be also evaluated on mouse cells as a prerequisite to anticancer immunotherapy assay in mouse model.

We first studied the invasion and survival capacity of $N$. caninum tachyzoites in mouse bone marrow dendritic cells (BMDCs) and human blood dendritic cells (DCs), and their respective induced cytokine expression patterns.

We observed that $N$. caninum tachyzoites had entered, survived and multiplied within human DCs demonstrating for the first time that a strictly nonzoonotic protozoan could infect and proliferate in human DCs (figure 1A). We also demonstrated that human DCs secreted proinflammatory cytokines such as IL-12, TNF- $\alpha$, IL-10 and IL-6 in response to stimulation with live $N$. caninum tachyzoites (figure 1B). Similar infectious capacity and cytokine induction profiles were observed in mouse cells including BMDCs (figure 1C,D), and in mouse macrophages and neutrophils (online supplemental figure 1). However, in contrast to mouse BMDCs, human DCs failed to secrete those important innate cytokines when exposed to dead protozoa. Finally, soluble tachyzoite antigens were not able to activate murine or human DCs.

In context of immunotherapeutic treatment with $N$. caninum, those findings convincingly suggest that the use of live parasites is a sine qua non condition for inducing robust immune responses.

\section{Selection of the most immunogenic dose of $\boldsymbol{N}$. caninum tachyzoites for immunotherapy assay in mice}

To determine if $N$. caninum can induce a strong and early immune response without toxicity, mice were subcutaneously inoculated with several doses of $N$. caninum tachyzoites $\left(2 \times 10^{3}\right.$ to $2 \times 10^{7}$ per mouse). Significant humoral and cellular immune responses were 
A
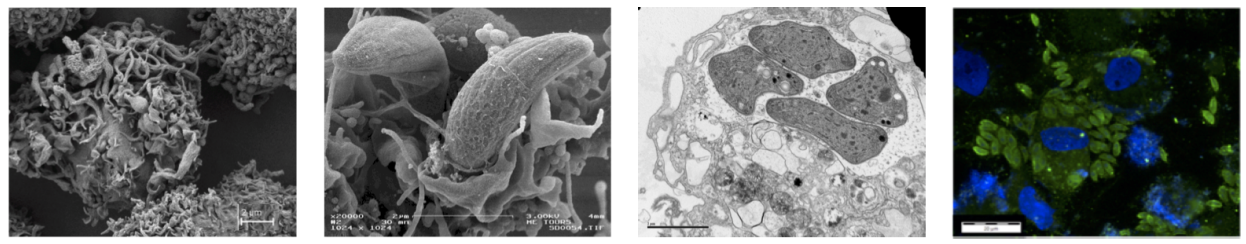

B
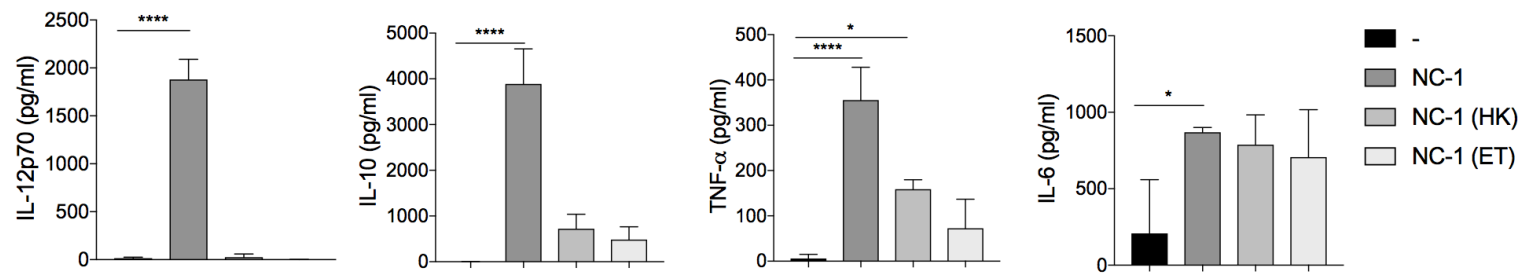

C
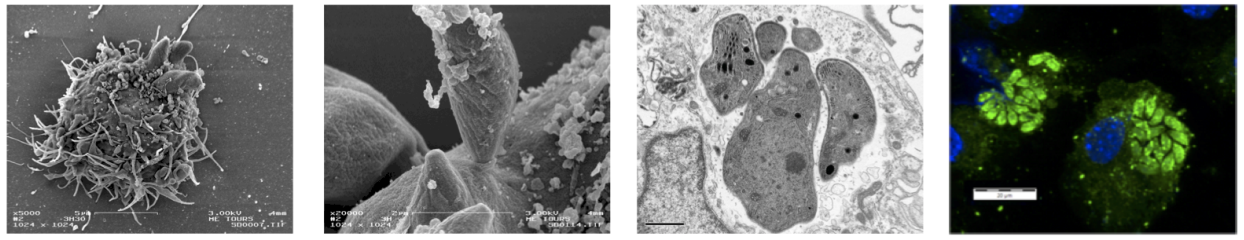

D
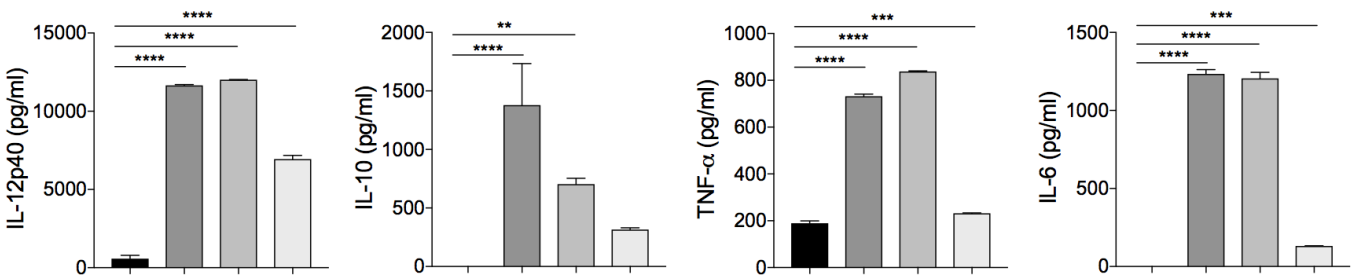

-

$\square \mathrm{NC}-1$

$\square \mathrm{NC}-1(\mathrm{HK})$

$\checkmark \mathrm{NC}-1(\mathrm{ET})$

Figure 1 Immunostimulatory properties of Neospora caninum in vitro. At 4 hours and at 24 hours after infection with $N$. caninum tachyzoites (mutiplicity of infection (MOI) 3), mouse bone marrow dendritic cells (BMDCs) and human dendritic cells were fixated and prepared for electron microscopy or immunofluorescence assays were performed. First step of $N$. caninum infection (at 4 hours, 3 left panels) and cellular multiplication (at 24 hours, right panel) in human dendritic cells (A) and in mouse BMDCs (C) were thus visualized. For induction of cytokine expression, mouse BMDCs and human dendritic cells were cultured with or without $N$. caninum tachyzoites (MOI 1), alive or dead (as either whole dead organisms: heat-killed (HK) or as a total antigen extract from the protozoa: ET). After 24 hours of stimulation, supernatants were collected and the specified cytokines were assayed from the different lots of human dendritic cells $(B)$ and of mouse BMDCs $(D)$. ${ }^{*} P<0.05 ;{ }^{* *} p<0.01 ;{ }^{* \star} p<0.001$; ${ }^{* * * *} \mathrm{p}<0.0001$.

observed via production of $N$. caninum-specific IgG and of IFN- $\gamma$ in sera (online supplemental figure 2B-C). In parallel, survival of infected mice was recorded daily (online supplemental figure 2A). Except for the lowest dose of $2 \times 10^{3}$, the amount of specific IgG induced was essentially the same for all other doses. Concerning the cellular immune response, the highest doses $\left(2 \times 10^{6}\right.$ and $2 \times 10^{7}$ ) of protozoa were the most immunogenic as we observed a secretion of IFN- $\gamma(\cong 500 \mathrm{pg} / \mathrm{mL})$ in sera from the second day of infection. For lower doses, an IFN- $\gamma$ production was observed only after a week. As the dose of $2 \times 10^{7}$ tachyzoites induced the death of all mice after 1 week, we decided to choose the dose of $2 \times 10^{6}$ parasites with a survival percentage of $60 \%$ for immunotherapy assays in mice.

\section{Intratumorous delivery of $\boldsymbol{N}$. caninum induces therapeutic antitumor effect}

The antitumor effect of $N$. caninum was evaluated using the tumor-bearing mouse model wild type (WT) EG7
(PD-L1 ${ }^{\text {lo }}$ EG7; OVA-expressing EL4 lymphoma). The EG7 cells were implanted in the right flank of C57BL/6 mice. To determine an optimal protocol and to assess whether the intratumorous injection of $N$. caninum could significantly inhibited tumor growth, $2 \times 10^{6}$ tachyzoites were injected 4 days after implantation with or without a second injection 3 days after (figure 2A).

We observed that intratumorous injection of protozoa significantly reduced tumor growth (figure 2B). Regardless of the protocol, tumors stopped growing 1 week after treatment and then rapidly regressed. Tumors from mice treated twice were undetectable in at least $85 \%$ of cases within 22-25 days, leaving a scar that disappears in the following days (figure $2 \mathrm{C}$ and $\mathrm{J}$ ). If a drastic regression of tumors was observed for mice treated only once, very small tumors still persisted at the end of the protocol $\left(<400 \mathrm{~mm}^{3}\right)$ suggesting the need for two injections. Moreover, no recurrence has occurred on treated mice $>40$ days after treatment (data not shown). 
A

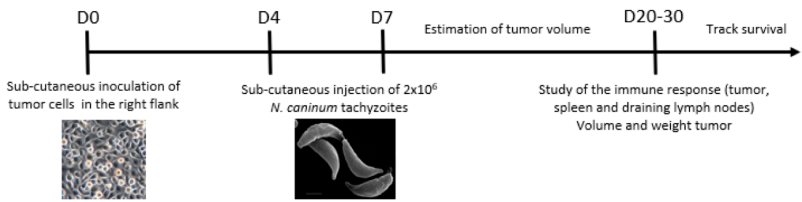

B

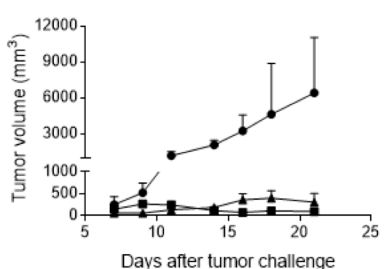

D

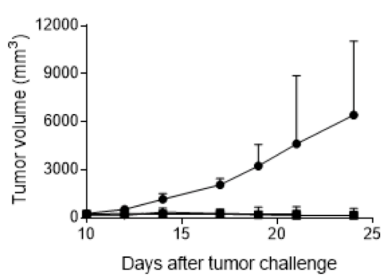

$\mathrm{F}$

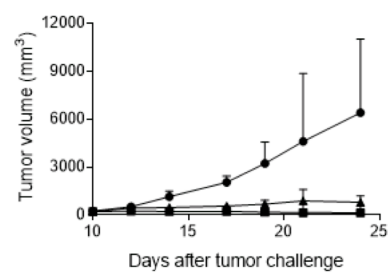

$\mathrm{H}$

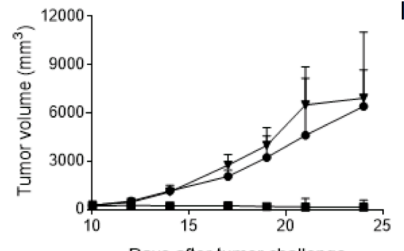

Days after tumor challenge
C
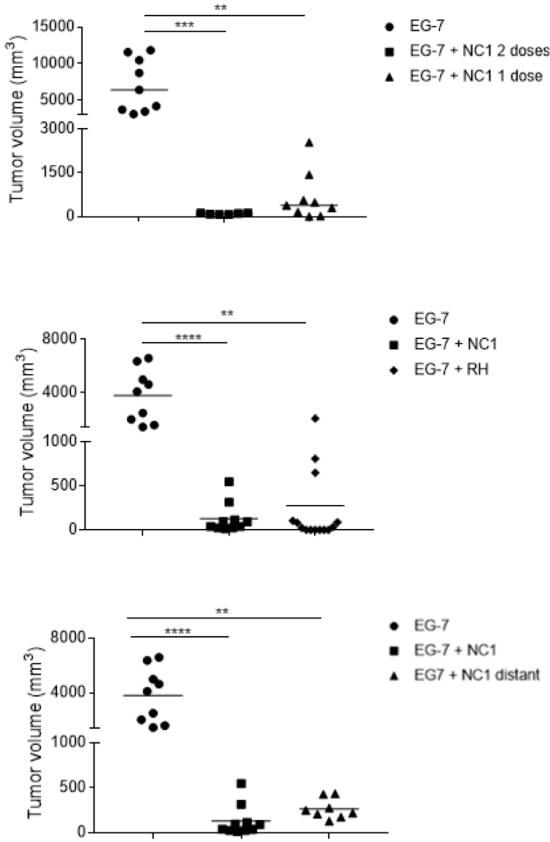

- EG-

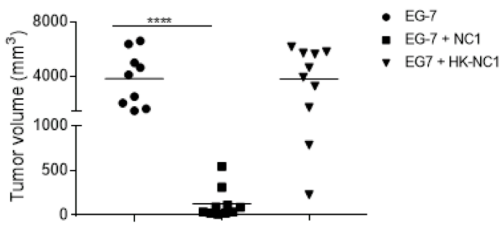

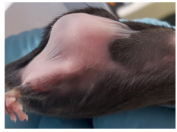
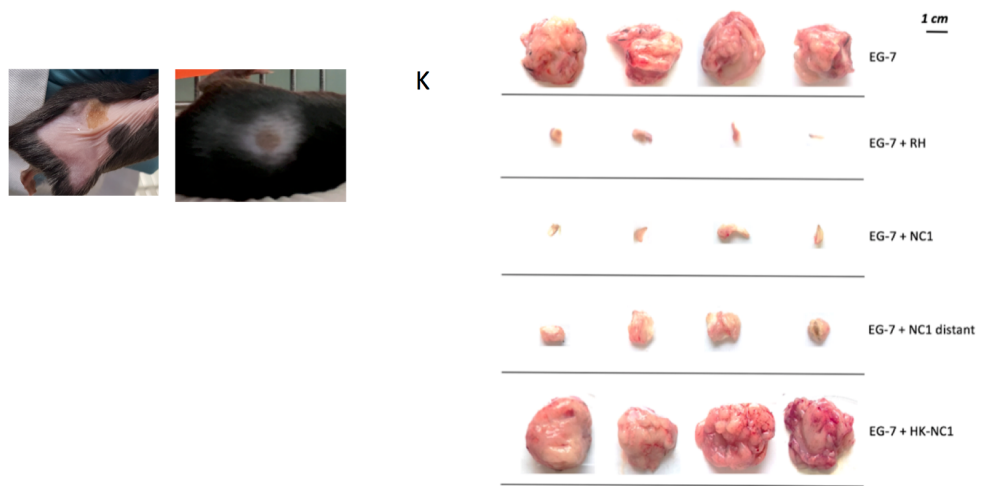

Figure 2 Tumor regression comparing Neospora caninum versus Toxoplasma gondii treatment in vivo. (A) Protocol of subcutaneous treatment with $N$. caninum $(\mathrm{NC1})$ or $T$. gondii $(\mathrm{RH})$ tachyzoites. EG7 cells $\left(5 \times 10^{5}\right)$ were inoculated subcutaneously in C57BL/ 6 mice and $N$. caninum tachyzoites $\left(2 \times 10^{6}\right)$ were injected intratumorally 4 or 4 and 7 days later: evolution of tumor development (B) and tumor volume at day 21 (C). T. gondii tachyzoites (500) were injected intratumorally on the same schedule: evolution of tumor development (D) and tumor volume was made at day 24 (E). Intratumorous and distant (flank opposed to the tumor) treatment with $N$. caninum at D4 and D7 postimplantation of EG7 cells have been compared: evolution of tumor development (F) and tumor volume was made at day $24(\mathrm{G})$. Intratumorous treatment with alive or dead (heat-killed: HK-NC1) $N$. caninum at D4 and D7 postimplantation of EG7 cells have been compared: evolution of tumor development $(\mathrm{H})$ and tumor volume was made at day 24 (I). (J) Fibrosis observed after N. caninum tachyzoites injection. (K) Macroscopic tumor size posttreatment with $T$. gondii tachyzoites (intratumorous) and $N$. caninum tachyzoites (intratumorous, distant or HK) at day 24 . For each experiment, there are between 8 and 10 mice per group. ${ }^{\star \star} \mathrm{P}<0.01 ;{ }^{\star \star \star} \mathrm{p}<0.001 ;{ }^{\star \star \star \star} \mathrm{p}<0.0001$. 
As $N$. caninum exhibited strong antitumor properties in a non-natural host, suggesting a potential efficacy in humans, we decided to compare its capacity with $T$. gondii, a naturally infectious parasite of rodents and humans, which had been shown to reverse tumor-associated immunosuppresion and to stimulate effective immune responses to eradicate established tumors. ${ }^{18}$ After two injections of tachyzoites at the site of the tumor, both groups showed a strong inhibition of tumor development, and total clearance of tumors in some cases within 25 days (figure 2D, E and K). Thus, both $N$. caninum and $T$. gondii showed similar therapeutic properties against the EG7 tumor regardless of the mice being a natural or non-natural host of the agent used.

We then tested if $N$. caninum could still be effective if injected as a distant site from the tumor. As well as intratumorous delivery, remote inoculation succeeded to drastically decrease distant tumors. However, very small tumors persisted and total eradication was not obtained suggesting that $N$. caninum administration in the tumor microenvironment (TME) enhances its efficacy (figure 2F, G and K). Dead protozoa (heat-killed) failed to induce such tumor regressions; which indicated the need of live protozoa, for a direct or indirect oncolytic activity of $N$. caninum (figure $2 \mathrm{H}, 1$ and $\mathrm{K}$ ). To test the long-term effect of tumor treatment, mice in which a complete tumor regression had occurred were re-implanted with EG7 cells (25 days after the first implantation, on the opposite flank). While $100 \%$ of the mice injected for the first time with EG7 develop tumors, only $16,7 \%$ of the previously treated mice (2 out of 12 mice) harbored small tumors (50 vs $350 \mathrm{~mm}^{3}$ in the control group), within 2 weeks. We observed that all remaining mice rejected the tumor rechallenge and remained tumor-free for 14 days. In naive mice, tumors can be observed as soon as 6 days postinjection of tumor cells and then reach an important volume of approximately $500 \mathrm{~mm}^{3}$. Therefore, an absence of tumors in 14 days allow us to conclude that Neospora induce a protection against a rechallenge with EG7 tumor in those mice, showing that $N$. caninum therapy also induces a long-term antitumor immunity (online supplemental figure $3 \mathrm{~A}, \mathrm{~B})$.

Finally, we explored the effects of pre-existing anti-Neospora immunity on therapeutic efficacy. We infected mice with $2 \times 10^{6}$ tachyzoites of $N$. caninum and used the same treatment regimen 1 month after this first infection. We observed that primary infection did not affect the capacity of protozoa to induce a protective antitumor response as we obtained the same rate of tumor regression (online supplemental figure 3C).

These results demonstrate a durable efficacy of the antitumorous therapeutic treatments with $N$. caninum, preventing potential relapses without impact of a preexisting $N$. caninum immunity, suggesting the possibility of repeated treatment without efficacy loss.

\section{N. caninum does not persist in the organism following the} induction of tumor regression

In order to decipher the antitumor potential of $N$. caninum, we investigated different possible mechanisms of protozoan-mediated tumor regression/destruction: 1) direct cytotoxic activity (oncolytic pathogens), 2) induction of antitumor immune response and 3) reprogramming the tumor microenvironment.

In vitro, transmission electron microscopy and immunofluorescence revealed that $N$. caninum tachyzoites were able to infect and multiply inside thymoma cells and lyze them (figure 3A). Four days after injection in mice, fluorescence microscopy revealed the presence of parasitophorous vacuoles (the replicative structure of Apicomplexa) in the tumor tissue, proof of the active replication of $N$. caninum in the TME (figure 3B, right panel). $N$. caninum was detected by qPCR in the tumor until 11 days post-treatment, but in quantity lower than the initial injected dose. However, beyond day 18 post-treatment, $N$. caninum was no longer detectable in the tumor or peripheral organs: spleen, brain and liver suggesting a natural clearance of the infectious agent by the mouse immune system (figure 3B). On the contrary, T. gondii was still detected in the tumor 25 days after the first injection, and in quantity far greater that the initial injected dose (200fold), showing the high multiplication, and persistence abilities of T. gondii compared with $N$. caninum, despite similar antitumor efficacy. These results strengthen the interest, in efficacy and safety, of using a non-naturally infectious agent as a therapeutic, as N. caninum displays strong antitumor properties and is then naturally cleared from the organism.

\section{$N$. caninum infection induces a measurable, systemic immune response and reprograms the tolerogenic tumor microenvironment}

We evaluated systemic immune cell activation induced by $N$. caninum at blood and spleen levels. Four days after intratumorous inoculation of $N$. caninum tachyzoites, we observed an increase level of circulating IFN- $\gamma$, high levels of IFN- $\gamma$ and IL-12 (online supplemental figure 6A) and low levels of IL-5, IL-10 and IL-17 in spleen with recruitment of DCs, macrophages and natural killer (NK) cells (online supplemental figure 6B). Of note, EG-7 cells being OVA expressing cells, splenocytes were stimulated in vitro with OVA for 72 hours, but no difference in expression of the 10 tested cytokines (including IFN- $\gamma$ ) was observed compared with unstimulated cells, therefore suggesting that the protection mechanisms observed are not OVA dependent (data not shown).

We then investigated in vitro, the ability of $N$. caninum to alter tolerogenic cells. BMDCs were cultured in presence of vitamin $\mathrm{D}_{3}$ to induce a tolerogenic phenotype, characterized by a strong secretion of IL-10 and a very low secretion of IL-12 compared with control BMDCs (figure 3C). We confirmed that N. caninum tachyzoites were able to infect tolerogenic DCs (figure 3C) and, 18 hours after infection, to drive the tolerogenic DCs in a 
A
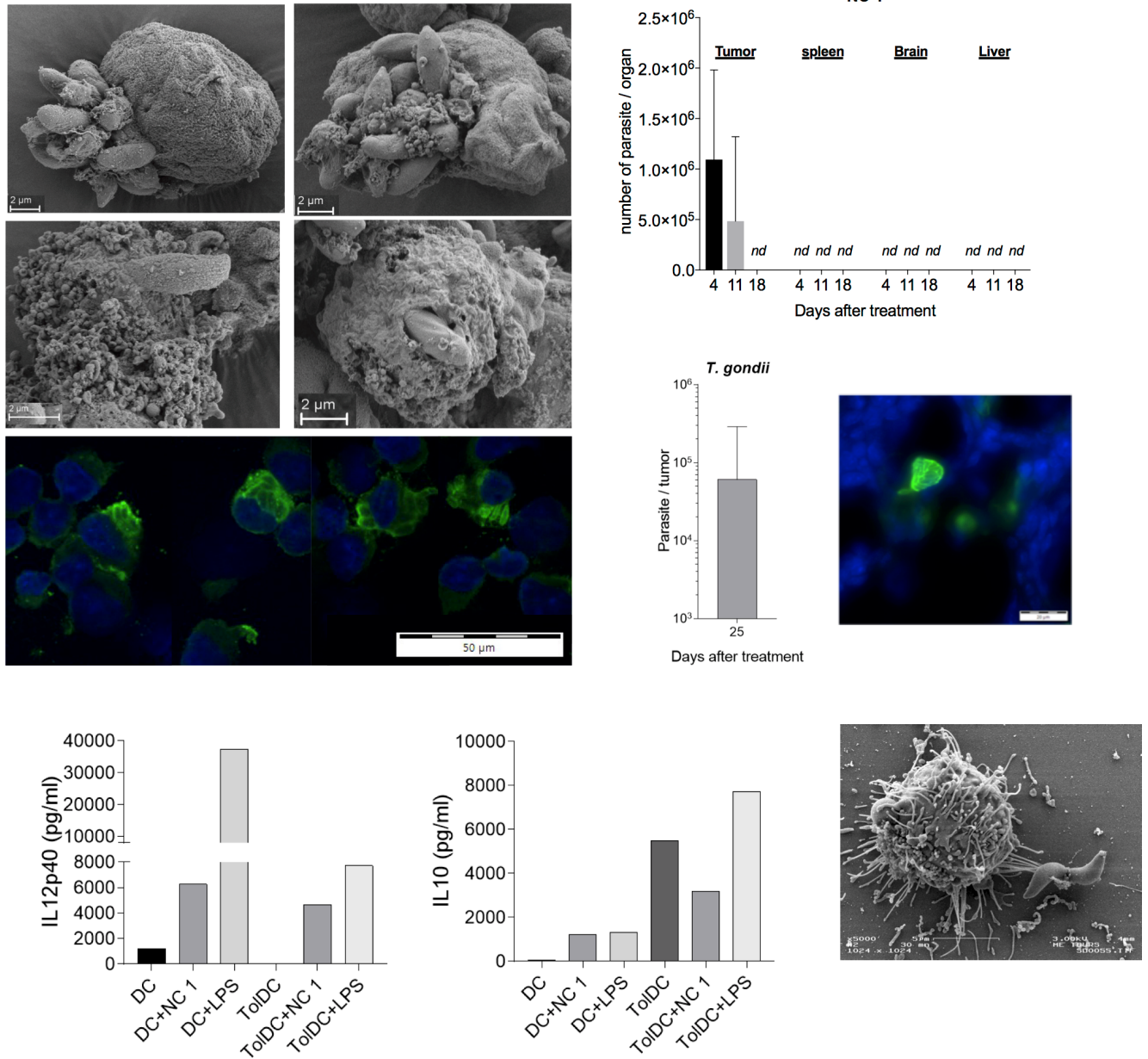

D
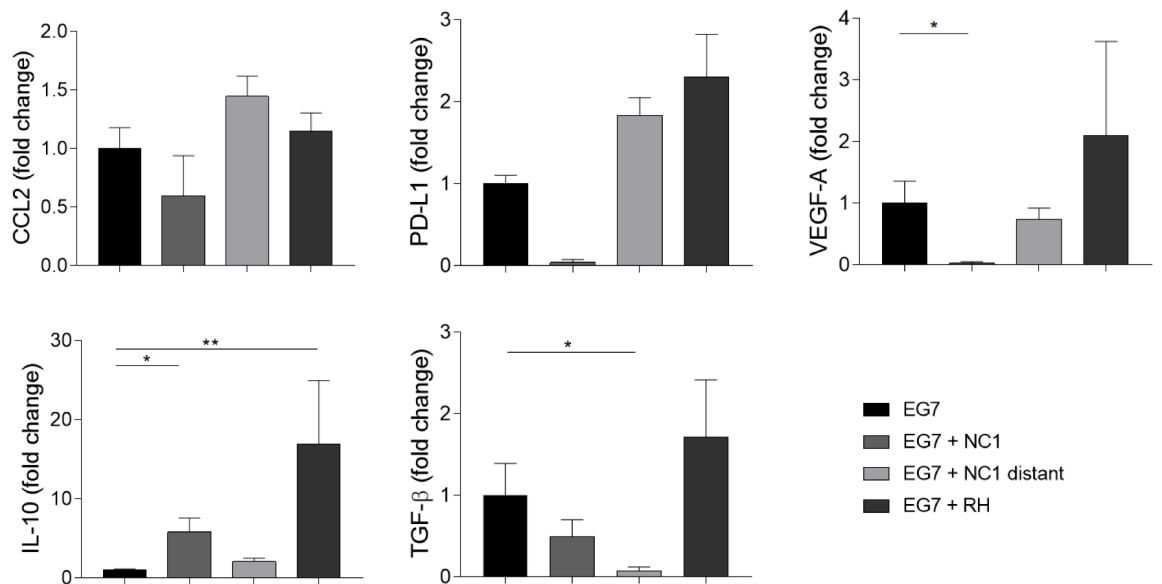

Figure 3 Non-persistence of Neospora caninum following tumor microenvironment reprogramming. In vitro, EG7 cells were cultured with $N$. caninum tachyzoites (MOI 3), then, 2 hours or 4 hours postinfection, cells were fixated for scanning electron microscopy; 24 hours postinfection, cells were fixated for immunofluorescence. The first phases of $N$. caninum infection (A, 4 top panels) and cellular multiplication (A, bottom panel) in mouse tumor EG7 cells are visualized. In vivo, EG7 cells $\left(5 \times 10^{5}\right)$ were inoculated subcutaneously into C57BL/6 mice and administered $N$. caninum $\left(2 \times 10^{6}, \mathrm{n}=3\right)$ or Toxoplasma gondii $(500$, $\mathrm{n}=4$ ) tachyzoites intratumorally 4 and 7 days later. Tumors and organs were collected at different times and the presence of the protozoan detected by quantitative PCR (qPCR) (B). Immunofluorescence assays were performed on tumor cryosections in order to visualize $N$. caninum tachyzoites (in green) 5 days after tumor inoculation (B). In vitro, mouse bone marrow dendritic cells (BMDCs) were cultured in presence of vitamin $\mathrm{D}_{3}$ to induce a tolerogenic phenotype. Mice BMDCs (DCs) and tolerogenic BMDCs (TolDCs) were cultured with $N$. caninum tachyzoites (NC1, MOI 1). Eighteen hours postinfection, secretion of interleukin (IL)-10 and IL-12 by infected and uninfected cells were compared (C) and electron microscopy on infected tolerogenic BMDCs were performed (C). In vivo, 21 or 24 days after EG7 cells inoculation and N. caninum (NC1) or T. gondii (RH) treatment, tumors were collected, dissociated and assayed for various immunosuppressive molecules (D), $n=10$ mice per lot. ${ }^{*} P<0.05$; ${ }^{\star *} p<0.01$. 
non-tolerogenic pattern, once again secreting high levels of IL-12 and low level of IL-10 as compared with control uninfected cells.

Analysis of common immunosuppressive factors, ex vivo, revealed that $N$. caninum treatment induced a reduction of factors associated with poor prognosis: VEGF-A, PD-L1, IL-10 and TGF- $\beta$ profile within the EG-7 TME (figure 3D). The favorable capacity seemed specific to $N$. caninum in contrast to $T$. gondii that induced an increased pattern of poor prognostic factors (figure 3D).

Together, those results show that N. caninum is able to reprogram tolerogenic cells and reverse the in vivo immunosuppressive environment into an immune-competent antitumor environment.

\section{N. caninum recruits immune cells in the tumor microenvironment to promote an effective $\mathrm{T}$ helper 1 immune responses}

Generation of an efficient tumor-specific immune response is crucial to sustain tumor control. Cellular and molecular mechanisms underlying protective effects of $N$. caninum were also studied at tumor level and tumor infiltration was characterized by immune cell phenotyping and cytokine secretion. Hematein-phloxin-saffron stained tumors revealed that almost no necrosis was observed in untreated tumors (median necrotic area $=3.1 \%$ of the tumor area) while large areas of necrotic tumor cells were observed in mice treated with live $N$. caninum (median necrotic area $=35.8 \%$ in NC1-treated group) as shown in figure 4A,B. Necrotic areas within NC1-treated tumors were infiltrated with neutrophils with hypersegmented nucleus, a histological feature of 'activation' (N1) as compared with untreated tumors infiltrated with neutrophils of less segmented (ring-shaped) nucleus suggesting an 'immature' (N2) phenotype (figure 4C).

Histological observation and confocal mosaic reconstitution of large section of the tumor parenchyma of untreated mice showed a dense network of EG7 cells $\left(\mathrm{CD}^{+}\right)$without necrosis (figure $4 \mathrm{~A}$ and $\mathrm{D}$ ), with regularly scattered macrophages $\left(\mathrm{CD} 68^{+}\right)$and few neutrophils $\left(\mathrm{Ly}_{6} \mathrm{G}^{+}\right)$.

Following NC1 treatment, the parenchyma of the tumor showed a dismantled cellular structure (figure 4A and E) highly infiltrated with neutrophils and macrophages, with EG7 cells $\left(\mathrm{CD}^{+}\right)$harboring a necrotic phenotype (altered DAPI staining) and highly infiltrated with clusters of neutrophils $\left(\mathrm{Ly}_{6 \mathrm{G}}{ }^{+}\right)$intermixed with macrophages $\left(\mathrm{CD}^{+} 8^{+}\right.$) (figure $\left.4 \mathrm{E}\right)$. Higher magnification of tumor sections from NC1-treated mice clearly suggests the close interaction of neutrophils and macrophages within those inflammatory clusters as indicated by the presence of merged area (yellow) of Ly6G and CD68 staining (figure 4F). Three-dimensional reconstitution of $\mathrm{Z}$ stacks from confocal images of the tumor parenchyma of NC1-treated mice confirms those interactions within areas of dense infiltrates (figure $4 \mathrm{H}$ ) on the contrary of untreated mice (figure 4G). Finally, the staining of $N$. caninum tachyzoites within the tumor 5 days after the first treatment (so before Neospora clearance) revealed that the tissue distribution of Neospora does not seem to follow a particular pattern as tachyzoites can be observed in all areas of the tumor as displayed on large section images (figure 4I).

Moreover, we can assume that Neospora can invade immune cells in vivo, as tachyzoites were colocalized with macrophages (figure 4I and J) within the TME.

We investigated by flow cytometry the immune cell infiltration in the TME. The total amount of myeloid cells was significantly higher in mice treated intratumorally with $N$. caninum. An 8-fold increase of neutrophils was observed in the tumor, associated with a 3.3-fold increase of macrophages $\left(\mathrm{F} 4 / 80^{+}\right.$cells) (figure $\left.5 \mathrm{~A}\right)$. The number of lymphoid cells also increased in the treated groups, with high infiltration of NK cells (4.4-fold), CD8 ${ }^{+}$ $\mathrm{T}$ cells (13-fold) and $\mathrm{CD} 4^{+} \mathrm{T}$ cells (2.4) suggesting the development of innate and adaptive immune responses (figure 5A). A somewhat similar profile was observed with the T. gondii treatment. Still, T. gondii seems to induce preferentially a recruitment of macrophages and B cells in the tumor, while $N$. caninum treatment induces preferentially the recruitment of neutrophils and $\mathrm{CD} 8^{+}$ T cells.

A similar profile-to a lesser extent—was observed in tumors of mice with remote site treatment. Moreover, as expected, no variation in cell population was found in tumors of mice treated with heat-killed parasites (data not shown).

The increase of those cell populations was correlated with a strong increase of $\mathrm{T}$ helper $(\mathrm{Th}) 1$ profile cytokines in the TME. Indeed, $N$. caninum treatment induces a strong increase in the secretion of IL-12, IFN- $\gamma$, IL-2 and TNF- $\alpha$ in the TME (figure 5B). As expected, a similar profile was observed in the remotely treated group, but with a lower increase, correlating with the immune cell populations data.

As a matter of comparison, T. gondii strongly increased the secretion of a broad range of cytokines, and the effect on Th1 profile cytokines was similar to the one observed with $N$. caninum.

\section{$N$. caninum antitumorous activity is dependent on macrophages, NK cells and CD8 ${ }^{+} \mathrm{T}$ cells}

In order to assess the respective involvement of immune cells in the Neospora-induced antitumor effect, we administered anti-CD4, anti-CD8, anti-NK1.1, anti-Ly6G monoclonal antibodies (mAbs) or chlodronate liposomes (macrophages depletion) from D1 after Neospora injection, to deplete the respective cell populations. While injection of anti-NK1.1, anti-CD8 mAbs and chlodronate liposomes completely abolished the antitumor activity of Neospora, anti-Ly6G and anti-CD4 mAb did not have any effect on the tumor regression (figure 6). These data show the critical role of NK cells, $\mathrm{CD}^{+} \mathrm{T}$ cells and macrophages in the protection processes induced by $N$. caninum treatment. 

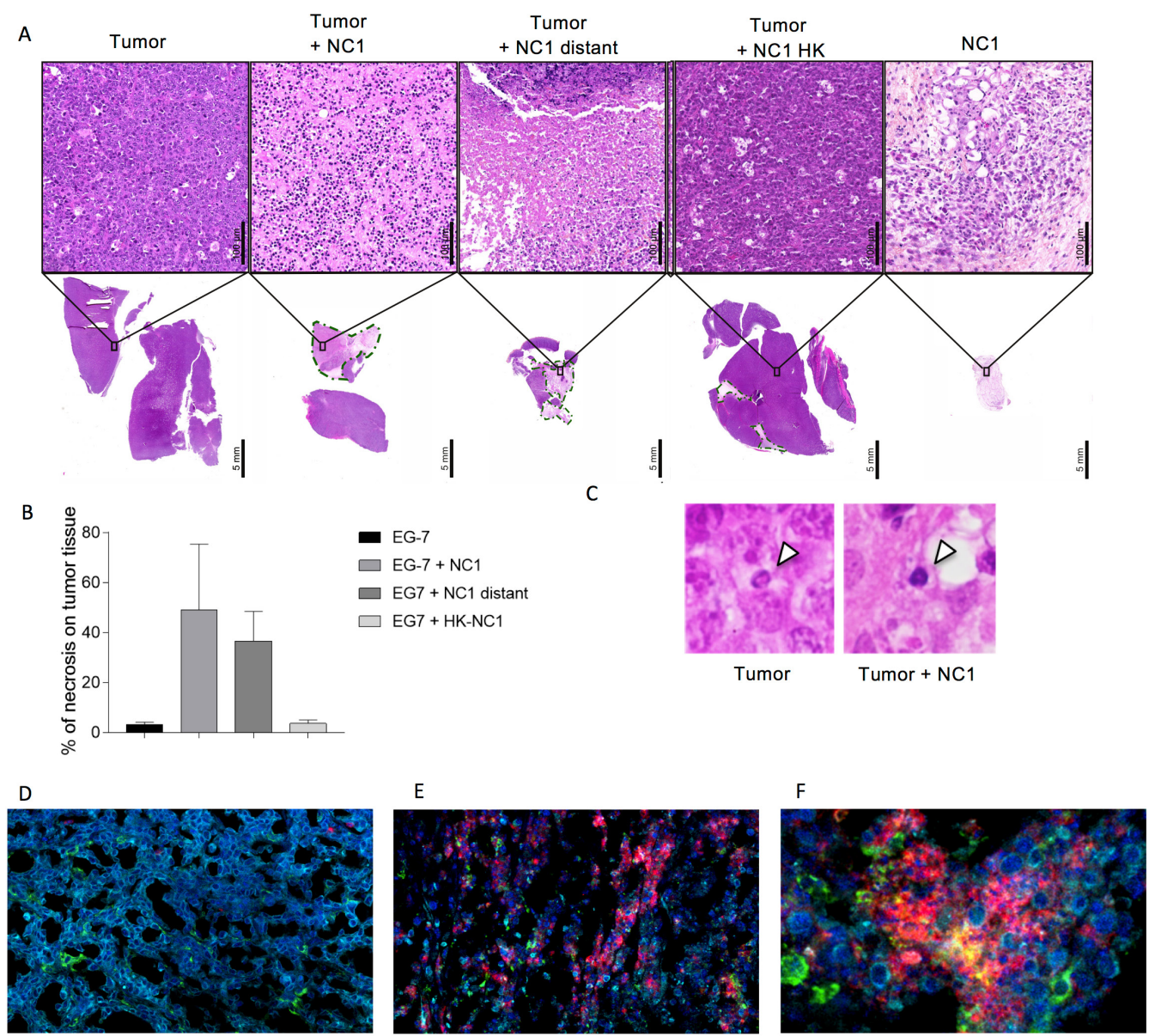

G

$\mathrm{H}$
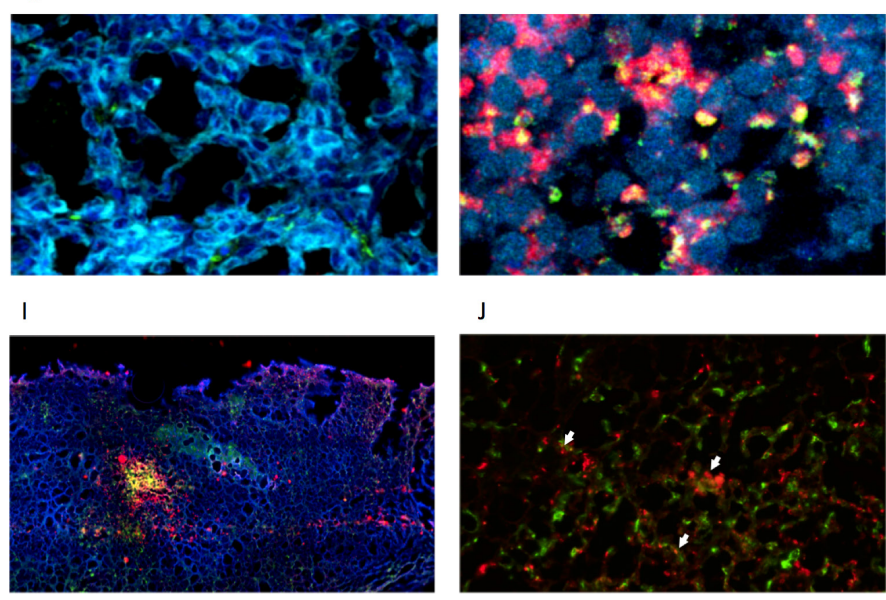

Figure 4 Tissue necrosis and cellular network structure of EG7 tumor following Neospora caninum treatment. Twentyfour days after EG7 cells inoculation and $N$. caninum (NC1) treatment, tumors were collected for histological analysis and immunofluorescence staining, respectively. Representative specimens from experimental and control groups are depicted (hematein-phloxin-saffron staining, bars $=5 \mathrm{~mm}$ and $100 \mu \mathrm{m}$, respectively) (A). Percentage of necrotic areas, harboring pyknotic, dark nuclei, intermixed with an inflammatory infiltrate composed of neutrophils and macrophages within control and treated tumors were evaluated (B), between 3 and 5 mice per lot. Phenotypes of infiltrating neutrophils in control tumor: ringshaped/banded nucleus/slightly segmented suggesting an immature phenotype or N2 neutrophil and in NC1-treated tumor: hypersegmented nucleus suggesting a mature phenotype or N1 neutrophil (C). Representative confocal images of EG7 tumor 8 $\mu \mathrm{m}$ cryosections: mosaic reconstitution of large sections from untreated (D) and NC1-treated mice (E) and higher magnification of tumor sections from NC1-treated mice (F). Tumors were labeled with anti-Ly-6G for neutrophils (red), anti-CD3 for EG7 thymoma cells (cyan), anti-CD68 for macrophages (green) and counterstained with DAPI (4',6-diamidino-2-phénylindole, for nuclei (blue). Representative three-dimensional reconstitutions of Z stack from untreated $(\mathrm{G})$ and $\mathrm{NC} 1 \mathrm{treated}(\mathrm{H})$ were performed. Five days after the first Neospora injection, tumor were collected and stained for Neospora (red) and macrophages (CD68, green) and acquisition of large section were taken (I), larger magnification images were observed to visualize colocalization (J). 

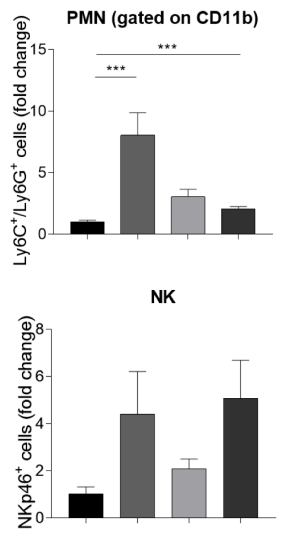

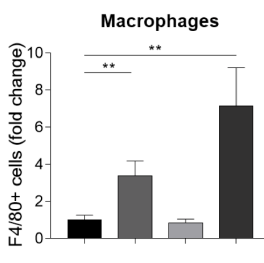

CD8+ T cells (gated on CD3+)

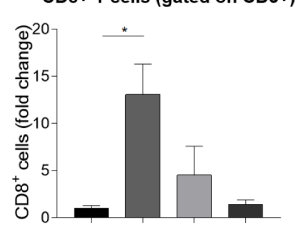

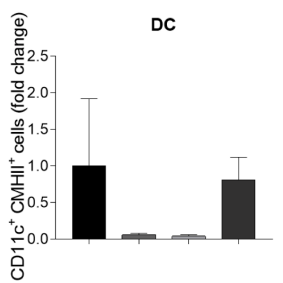

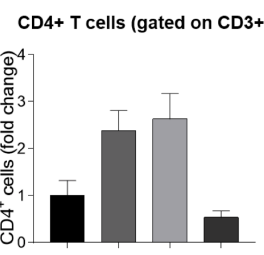

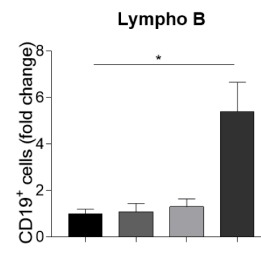

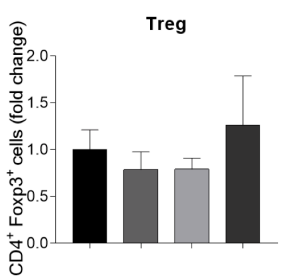

B
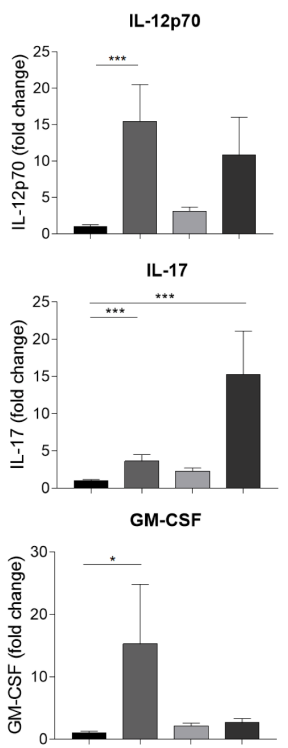
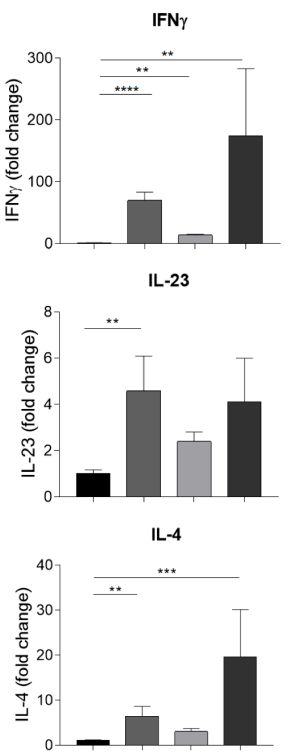

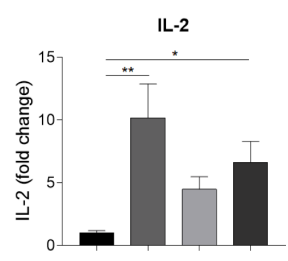

IL-18

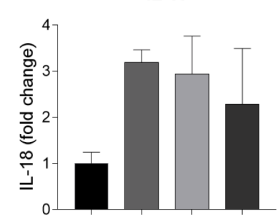

IL-5

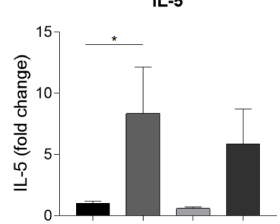

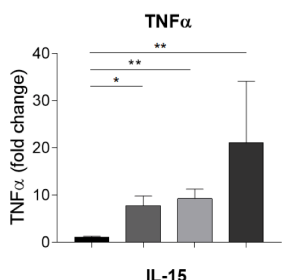

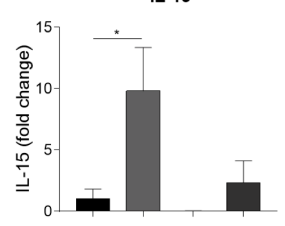

- EG7

- $E G 7+\mathrm{NC} 1$

$\square \mathrm{EG7}+\mathrm{NC} 1$ distant

- $\mathrm{EG7}+\mathrm{RH}$

Figure 5 Induction of a T helper (Th) 1 antitumor immune response after Neospora caninum treatment. EG7 cells $\left(5 \times 10^{5}\right)$ were inoculated subcutaneously in C57BL/6 mice and, 4 and 7 days later, $N$. caninum $\left(\mathrm{NC} 1,2 \times 10^{6}\right)$ or Toxoplasma gondii $(\mathrm{RH}, 500)$ tachyzoites were injected intratumorally. Twenty-four days after EG7 cells inoculation, tumors were collected and dissociated. The cell suspension was centrifugated and cells were resuspended for staining and flow cytometry analysis, $n=5$ mice per lot (A). Cytokines production in tumor dissociation supernatant was evaluated by ELISA or multiplex analysis, $n=10$ mice per lot (B). ${ }^{*} \mathrm{P}<0.05 ;{ }^{* \star} \mathrm{p}<0.01 ;{ }^{* \star *} \mathrm{p}<0.001 ;{ }^{* \star \star *} \mathrm{p}<0.0001$.

\section{N. caninum induces regression of human Merkel cell carcinoma}

In order to assess the effect of $N$. caninum on human tumors, we used a model of NOD/SCID mice bearing human MCC. After treatment, tumors of around $600 \mathrm{~mm}^{3}$ regressed to a measured volume of $200 \mathrm{~mm}^{3}$ (figure 7A). MCC that developed into established tumors (about $1000 \mathrm{~mm}^{3}$ at day 43 postinoculation) were injected with N. caninum tachyzoites (figure 7A). The volume of established tumors also regressed by threefold, 10 days after treatment.

As expected due to their extremely immunocompromised status, the NOD/SCID mice ended up dying of the $N$. caninum infection. Hence, qPCR analysis revealed an average of $2 \times 10^{8}$ tachyzoites per gram of tumor (figure $7 \mathrm{~B}$ ), showing that without the immune pressure, the protozoan has multiplied extensively within the tumor. Thus, the total and natural clearance of the parasite previously observed in WT mice is most probably related to their immune status, and not to a defect in the parasite ability to replicate in host cells (figure 3B).

The ability of the protozoan to infect and multiply in human tumor Merkel cells was confirmed in vitro by scanning electron microscopy and immunofluorescence (figure 7C). These data indicate the potential of $N$. caninum to infect and multiply in human tumor cells. 


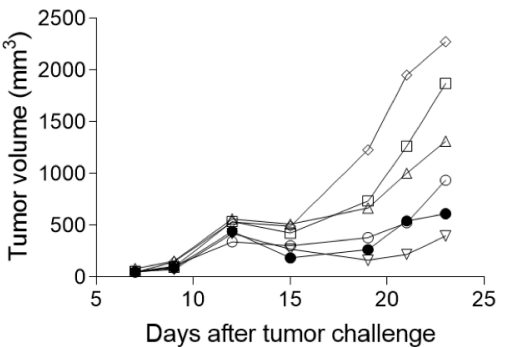

- PBS

$\square$ Clodronate liposomes

$\rightarrow$ Anti-CD4

$\triangle$ Anti-CD8

- Anti-neutrophiles

$\rightarrow$ Anti-NK
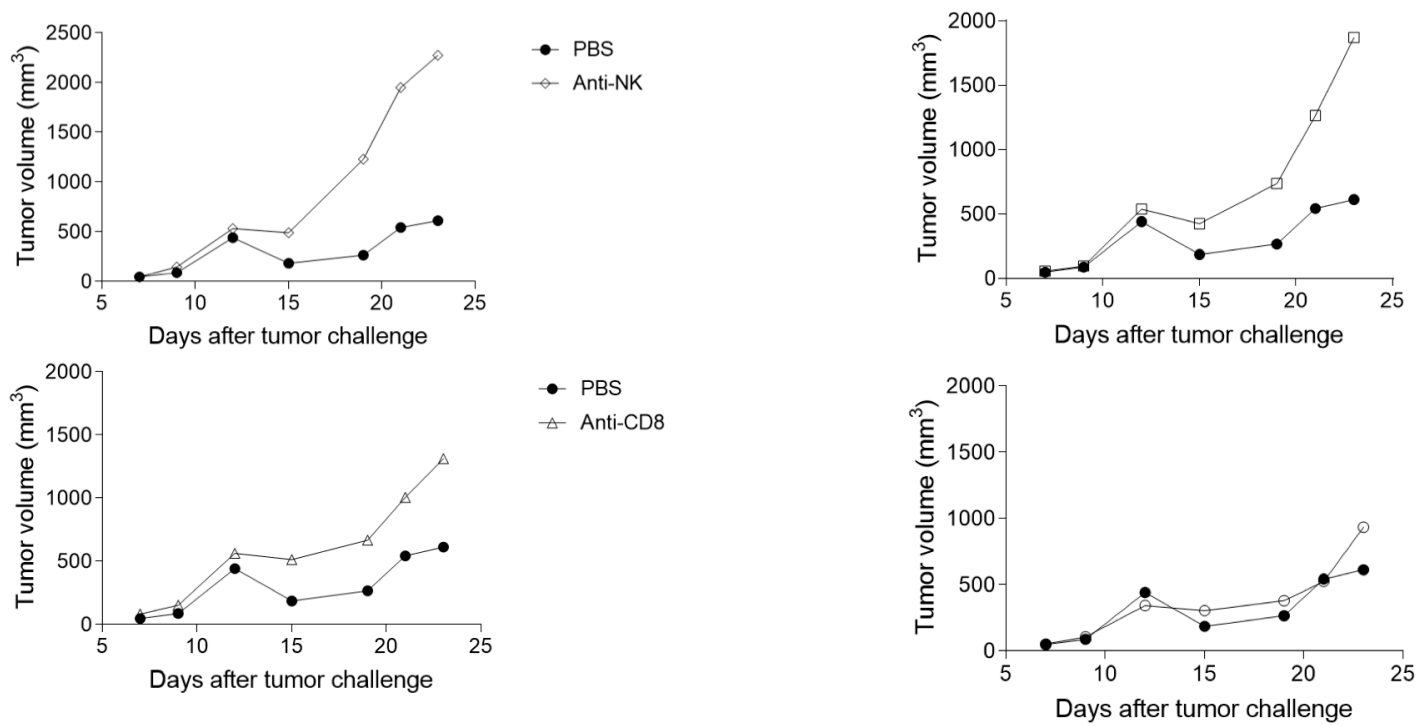

Figure 6 Impact of differential immune cell depletion on tumor regression following Neospora caninum treatment. EG7 cells $\left(5 \times 10^{5}\right)$ were inoculated subcutaneously in C57BL/6 mice and, 4 days later, $N$. caninum $\left(2 \times 10^{6}\right)$ tachyzoites were injected intratumorally. One day after $N$. caninum treatment and then every 2-3 days until sacrifice of the mice, anti-CD4, anti-CD8, antiNK1.1, anti-Ly6G monoclonal antibodies (mAbs) or chlodronate liposomes (macrophage depletion) were injected intratumorally. Evolution of tumor development was followed every 2-3 days. $n=6$ mice (phosphate-buffered saline (PBS)) and 10 mice (other lots). Individual values are shown in online supplemental figure 4).

\section{Engineered $N$. caninum secreting human IL-15 is able to enhance human immune cell activation}

Improving the protective effects of $N$. caninum seems essential in order to obtain a total protection in advanced or refractory tumors. To this aim, we engineered a $N$. caninum strain able to secrete the human IL-15 (crossreactive with mouse cells), associated with its sushi domain (alpha-subunit of the IL-15 receptor), increasing its stability, binding and biological abilities, to strongly induce the expansion of Th1-associated lymphocyte subsets and prevent their apoptosis in vivo. ${ }^{27}$

We first assessed that the engineered clones were able to secrete a biologically active form of the cytokine (figure 7D). We showed that supernatant of NC1IL15hRec cultures was able to induce IFN- $\gamma$ secretion by mouse splenocytes in vitro, 4 to 5 times more than supernatant from WT Neospora (figure 7E). The NC1-IL15hRec strain was thus able to secrete a functional IL-15 in its environment.

We then tested the effect of the NC1-IL15hRec strain on human cells. Human PBMCs were infected with NC1 and NC1-IL15hRec. After 24 hours, levels of IL-15 in the supernatant were only detectable for cells treated with NC1-IL15hRec (figure 7F). Then we observed that, as the recombinant IL-15, the NC1-IL15hRec strain was able to induce proliferation of human NK cells as shown by the increase of Ki67 expression by human NK cells (figure 7G). Meanwhile, WT N. caninum displayed a much lower increase of proliferation by NK cells. Moreover, while recombinant IL-15 was only able to induce proliferation, but not IFN- $\gamma$ secretion, by human PBMCs, NC1IL15hRec induced a strong IFN- $\gamma$ secretion by human PBMCs, much more than WT $N$. caninum (figure $7 \mathrm{H}$ ). Finally, EG7 bearing mice were treated intratumorally with NC1 or NC1-IL15hRec tachyzoites. This experiment revealed, after two injections of tachyzoites at the site of the tumor, an added-value of the IL-15 secretion by Neospora, as the volume of treated tumors was significantly smaller in tumor treated with NC1-IL15hRec compared with NC1 treatment (figure 7I and J). The analysis of immune cells in the TME revealed that the improved protection was also correlated with an increase of NK cells, CD8T cells and $\mathrm{CD} 4 \mathrm{~T}$ cells in the tumor microenvironment (online supplemental figure 4A). No added value was observed for the recruitment of DCs and macrophages. Of note, the level of expression of MHC-II on DCs or macrophages remained unchanged after Neospora treatment, regardless of the strain used, as shown in online supplemental figure 


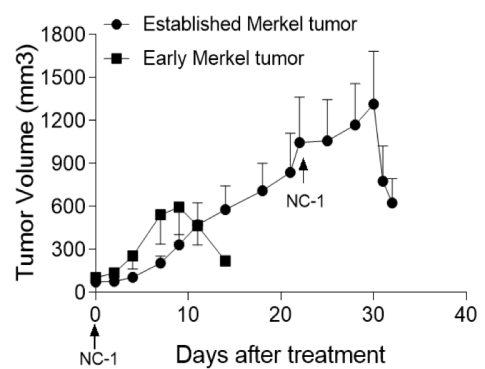

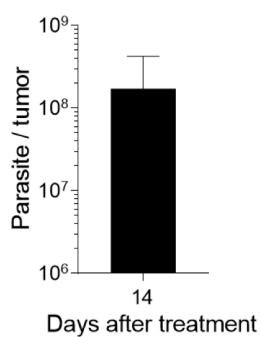

C

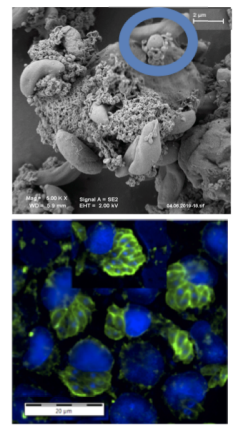

D

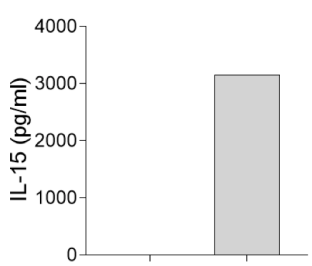

F

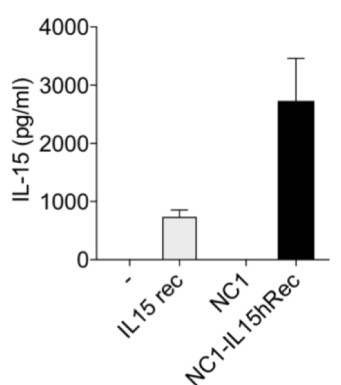

I

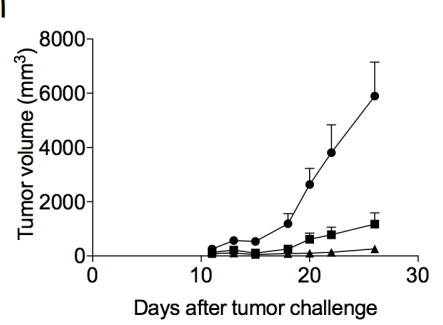

E

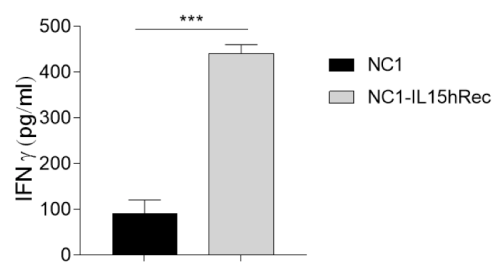

G

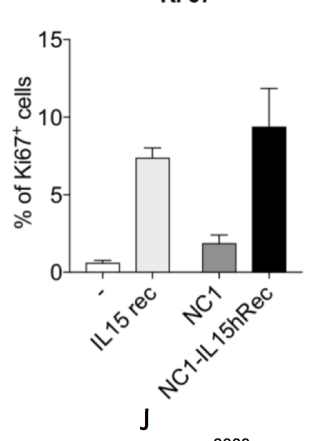

$\mathrm{H}$

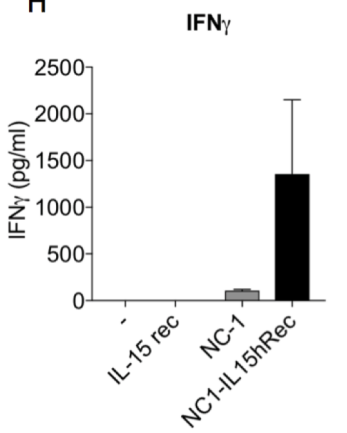

Figure 7 Evaluation of the oncolytic activity of Neospora caninum in human tumor. WaGa $\left(10^{7}\right.$, associated with $10 \%$ Matrigel $(10 \mathrm{mg} / \mathrm{mL}))$ cells were inoculated subcutaneously into the right flank of non-obese diabetic/severe combined immunodeficiency (NOD/SCID) mice. Twenty-one days later (early tumor) or 43 days later (established tumor), N. caninum $\left(2 \times 10^{6}\right)$ tachyzoites were injected intratumorally: evolution of tumor development was followed every 2-3 days, $n=4$ mice per lot (A). When mice died, tumors were collected and the presence of the protozoan was detected by quantitative PCR (qPCR) (B). In vitro, WaGa cells were infected (MOI 1) with $N$. caninum tachyzoites. With scanning electron microscopy and immunofluorescence, the ability of the protozoan to infect (C, top panel) and multiply (C, bottom panel) in human tumor Merkel cells was confirmed, at 4 hours and 24 hours, respectively. Supernatants of cultures of the engineered NC1-IL15hRec strain and NC1 strain were assayed for interleukin (IL)-15 48 hours after infection (MOI 0, 2) (D). Mouse splenocytes were infected with NC1-IL15hRec (MOI 1) and interferon (IFN)- $\gamma$ was assayed in the supernatant after 48 hours (E). Human peripheral blood mononuclear cells (PBMCs) were infected with NC1-IL15hRec or NC1 (MOI 1), and supernatants of cultures were assayed by ELISA 24 hours after infection (F, H). At the same point in time, cells were analyzed by flow cytometry (G). EG7 cells $\left(5 \times 10^{5}\right)$ were inoculated subcutaneously in C57BL/6 mice and N. caninum tachyzoites $\left(2 \times 10^{6}\right)$ of the NC1 or IL15hRec strain were injected intratumorally 4 or 4 and 7 days later: evolution of tumor development (I) and tumor volume at day $25(\mathrm{~J})$ are shown. $n=5$ for the EG7 group, $n=10$ for the treated groups.

5B). IL-15 was detected in the TME at D25, but was not detected in the blood of treated animals, suggesting a local secretion of IL-15 within the tumor, after Neospora treatment (online supplemental figure 5C).
Those data clearly demonstrated the added-value potential of an IL-15-armed strain of $N$. caninum that might enhance the already potent immunomodulatory properties of the WT protozoan. 


\section{DISCUSSION}

This study reports the first use of $N$. caninum as an immunotherapeutic agent against cancer and demonstrates the strong efficacy of this protozoan in both destroying the cancer cells and unleashing potent immune responses, leading to tumor regression and eradication.

The use of live micro-organisms for their antitumorous properties goes back more than a century, when in the 1890s, William Coley treated patients with cancer by injecting live bacteria intratumorally and first succeeded in obtaining total regression of malignant tumors. ${ }^{28}$ If this approach remained in the dark for decades, the recent rise of immunotherapy brought it back to light, essentially through oncolytic viruses. The first conceptual revolution of immunotherapy was the targeting or bypassing of the immunosuppressive signaling induced by the tumor and is currently supported by 11 immune checkpoint inhibitors and 2 CAR-T cell products, approved by the FDA. ${ }^{29}$ Combination of both these strategies seems especially promising, thus allowing a specific destruction of cancer cells and the abolishment of tumorous immunosuppression. ${ }^{30}$ The efficiency of cancer immunotherapy is based on these two aspects, and can be obtained with by a strong innate immune response initiated by a robust antigen presentation and priming process.

Oncolytic organisms trigger an antitumor immune response through direct lysis of the cancer cell and the subsequent release of tumor-associated antigens, damageassociated molecular patterns and pathogen-associated molecular patterns in the TME, altering the immunosuppressive environment of the tumor allowing activation of antigen presenting cells and alteration of the immunosuppressive environment of the tumor. Such effects induce tumor immune infiltration, potentially turning 'cold' tumors into 'hot'. In that matter, immunotherapy using the live microorganism N. caninum assesses all of these aspects. We first demonstrated in this study that $N$. caninum was able to induce strong activation of innate immune cells, correlated with an important secretion of IL-12 and TNF- $\alpha$ (figure 1 and online supplemental figure 1). In vivo, we demonstrated that $N$. caninum was able to thoroughly disrupt the tumor (figure 4), decreasing immunosuppressive factors (figure 3) and triggering immune cell infiltration. This tumor disruption was correlated to an increase in Th1 profile cytokine production in the TME (figure 5), thus leading to necrosis (figure 4), regression and/or eradication of a solid state tumor (figure 2).

The use of microorganisms meets strong interest but beset with challenges. Viral-based therapy is hampered by inefficient targeting, TME blocking and rapid clearance, while bacterial therapy suffers from toxicity. ${ }^{31}$ In contrast, an innovative immunotherapeutic cancer treatment based on the tachyzoite stage of Neospora, presents advantages. Neospora belongs to the phylum Apicomplexa, a group of eukaryotic organisms that bear an apical complex which allows them to penetrate a wide variety of cell membranes. This may explain how the agents can penetrate tumors and cancer cells despite impediments and lack of specific host cell receptors.

In terms of pay load capacity, the production of tachyzoites is no more limited than a virus bioproduction. Tachyzoites are very stable, can be easily produced by culture on mammalian cells and injected multiple times. Unlike viruses, $N$. caninum does not present a mutagenic risk and it does not integrate into the genome of the host cell.

Like oncolytic viruses or bacteria, $N$. caninum is a powerful stimulant of the innate immune system, a prerequisite to effective priming of adaptive immune responses against both foreign antigens and tumor-associated ones. After treatment with $N$. caninum, we indeed observed an increase of specific antibodies for either $N$. caninum antigen or EG-7 antigen (OVA) in the TME (data not shown). The protection mechanisms that we described were also reported with other strategies: Vaccinia virus treatment in a colorectal tumor model was followed by massive tumor necrosis correlated with the influx of neutrophils impairing the tumor vascularity. ${ }^{32}$ As observed with $N$. caninum in our model, NK cell depletion and CD8 depletion also impaired the efficacy of HSV therapy in melanoma $^{33}$ or adenovirus therapy in rectal tumors, ${ }^{34}$ respectively, highlighting the crucial role of both these cell populations in the tumor elimination, in an immunotherapy context. It appears that $N$. caninum induced similar immune responses as other oncolytic microorganisms and displayed unique properties. Its ability to efficiently invade many cell types thanks to its specialized organelles, allowed $N$. caninum to overcome many barriers that can be met by others agents. $N$. caninum is hence able to easily and actively invade tumor cells, regardless of the expression of a specific receptor at its surface. This active motility and invasive capacity of the tachyzoites could overcome the physical barrier formed endothelial cells met in solid tumors, representing a big challenge for delivery of oncolytic viruses. ${ }^{35}$ However, withal, we could suppose that $N$. caninum preferentially infects monocytes over other leukocytes, as described for $T$. gondii, ${ }^{36}$ hence favoring stimulation of innate immune cells within the TME. We demonstrated that $N$. caninum was able to invade immunosuppressive innate immune cells that shifted back to an immuno-active state (figure 3), thus countering the defensive immunosuppression established within the TME. Such countermeasure to impairment of immune defenses, concomitant with immune infiltration of the tumor, leads to strong production of Th1 profile cytokines in the TME (figure 5); all of those factors being crucial for the total eradication of a solid state tumor. Another hypothetical protection mechanism is infection and then modification of tumor cells, which promotes their recognition by the immune system, leading to the activation of an adaptive immune response specific for $N$. caninum, and for tumor antigens, as it was observed with oncolytic viruses. ${ }^{37}$ Future studies will be necessary to precisely investigate which cells are infected and what interactions occur between Neospora and the cells of the TME. Bioluminescent or fluorescent 
strains of Neospora will be a necessary tool to precisely answer those questions.

One issue raised about microbial-based cancer therapy pertains to potential toxicity. $N$. caninum has characteristics that make it stand out in that matter as well. First, $N$. caninum has never been described as pathogenic in humans, making it an interesting candidate compared with other viruses, bacteria or protozoan that have been explored in cancer therapy. Our data also showed that after initiating strong immunological responses, $N$. caninum was naturally cleared from the tumor and the entire organism (figure 3). Moreover, acquired immunity against $N$. caninum did not impair the efficacy of future treatment (online supplemental figure 3), suggesting the possibility of repeating injections of $N$. caninum tachyzoites through time, without a loss of efficacy against the tumor. Altogether, those data suggest that $N$. caninum is a novel, safe and very promising agent for the treatment of solid-sate tumors. The tumor regression induced by a distant administration of Neospora also suggests that a protective effect could be observed in distant diseases or metastasis, if Neospora is administered by a systemic route. This approach is currently under investigation in the laboratory.

However, treatment of advanced and/or refractory tumors might require enhanced antitumor responses and functions. This could be obtained by combinatory strategies or genetic engineering of the oncolytic agent(s). Accordingly, several armed oncolytic virus or bacteria have been developed, notably viruses encoding type $\mathrm{I}^{3839}$ or type $\mathrm{II}^{40} \mathrm{IFNs}$, to enhance their antitumorous efficacy. Neospora, as higher order eukaryotes, have a much larger genomic capacity than viruses or bacteria and can be relatively easy to engineer to carry one or more transgenic payloads. This translates as an ability to enable other molecules in a recombinant derivative and traffic them to tumor site(s) and into cancer cells. Arming of an oncolytic agent with the expression of a fusion protein of IL-15 and IL-15Ralpha had been explored and showed promising results with an engineered vaccinia virus in both colon and ovarian cancer model, ${ }^{41}$ where expansion of NK cells and CD8 T cells was observed. In our study, we established that the NC1-IL15hRec strain was able to induce both cell proliferation and IFN- $\gamma$ secretion by human PBMCs in vitro, thus reinforcing the immunostimulatory properties of $N$. caninum.

Altogether, our data suggest that through innate immune cell stimulation and, potentially, tumorassociated antigen release, $N$. caninum induces a specific adaptive immune response dependent on NK cells and CD8 $\mathrm{T}$ cells recruitment in the TME. Targeting these cells to enhance the antitumor responses through armed $N$. caninum might be the key to obtain total regression of tumors. Further studies will be necessary to develop an arsenal of different therapeutic N. caninum and assess their different mechanisms of action.

In summary, our study has revealed that the protozoan $N$. caninum can elicit potent antitumor immunity in vivo, in murine models of mouse and human tumors, and that modifying $N$. caninum to secrete the IL-15-IL15Ra complex in the microenvironment strongly augments its immunological properties. These data also highlight the potential of $N$. caninum engineered strains, to either secrete antitumor effectors, or express protein at its surface, extending the possible clinical applications of $N$. caninum to a wide range of cancer therapies.

\section{Author affiliations}

${ }^{1}$ Université de Tours, INRAE, ISP, F-37000, Tours, France

${ }^{2}$ INRAE, Université de Tours, ISP, F-37380, Nouzilly, France

${ }^{3}$ EA 4245 Cellules Dendritiques, Immuno-Modulation et Greffes, F-37000, Universite de Tours, Tours, France

${ }^{4}$ Inserm U1232, Faculté des Sciences, CRCINA, CHU d'Angers, Université Angers, Angers, France

${ }^{5}$ INSERM, Centre d'Etude des Pathologies Respiratoires (CEPR), UMR, 1100, Université de Tours, Tours, France

${ }^{6}$ Kymeris Santé, SA, F-37000, Tours, France

${ }^{7}$ Department of Pathology, Université de Tours, CHU de Tours, Tours, France

Acknowledgements The electronic microscopy data were obtained with the assistance of the IBiSA Electron Microscopy Facility of the University of Tours.

Contributors LL and AP performed all of the presented experiment, analyzed the data and wrote the manuscript. All authors participated in performing experiments and analyzing the data. ID-P supervised the entirety of the study.

Funding This work was funded by the ARD2020 Biomédicaments program (2017 00118200)

Competing interests No, there are no competing interests.

Patient consent for publication Not required.

Ethics approval Experiments were carried out in accordance with the guideline for animal experimentation (EU Directive 2010/63/EU) and the protocol was approved by the local ethics committee (CEEA VdL).

Provenance and peer review Not commissioned; externally peer reviewed.

Data availability statement Data are available on reasonable request. All data are available on reasonable request to the corresponding author (louis.lantier@ univ-tours.fr)

Supplemental material This content has been supplied by the author(s). It has not been vetted by BMJ Publishing Group Limited (BMJ) and may not have been peer-reviewed. Any opinions or recommendations discussed are solely those of the author(s) and are not endorsed by BMJ. BMJ disclaims all liability and responsibility arising from any reliance placed on the content. Where the content includes any translated material, BMJ does not warrant the accuracy and reliability of the translations (including but not limited to local regulations, clinical guidelines, terminology, drug names and drug dosages), and is not responsible for any error and/or omissions arising from translation and adaptation or otherwise.

Open access This is an open access article distributed in accordance with the Creative Commons Attribution Non Commercial (CC BY-NC 4.0) license, which permits others to distribute, remix, adapt, build upon this work non-commercially, and license their derivative works on different terms, provided the original work is properly cited, appropriate credit is given, any changes made indicated, and the use is non-commercial. See http://creativecommons.org/licenses/by-nc/4.0/.

\section{ORCID iD}

Louis Lantier http://orcid.org/0000-0003-3642-7500

\section{REFERENCES}

1 Ribas A, Wolchok JD. Cancer immunotherapy using checkpoint blockade. Science 2018;359:1350-5.

2 Schuster SJ, Svoboda J, Chong EA, et al. Chimeric antigen receptor $\mathrm{T}$ cells in refractory $\mathrm{B}$-cell lymphomas. $N$ Engl J Med 2017;377:2545-54.

3 Neelapu SS, Locke FL, Bartlett NL, et al. Axicabtagene ciloleucel CAR T-cell therapy in refractory large B-cell lymphoma. N Eng J Med 2017. 
4 Song S, Vuai MS, Zhong M. The role of bacteria in cancer therapy - enemies in the past, but allies at present. Infect Agent Cancer $2018 ; 13$.

5 Rothman J, Paterson Y. Live-Attenuated Listeria-based immunotherapy. Expert Rev Vaccines 2013;12:493-504.

6 Raja J, Ludwig JM, Gettinger SN, et al. Oncolytic virus immunotherapy: future prospects for oncology. j. immunotherapy cancer 2018;6.

7 Pol J, Kroemer G, Galluzzi L. First oncolytic virus Approved for melanoma immunotherapy. Oncoimmunology 2015.

8 Sedighi M, Zahedi Bialvaei A, Hamblin MR, et al. Therapeutic bacteria to combat cancer; current advances, challenges, and opportunities. Cancer Med 2019;19.

9 Zhou S, Gravekamp C, Bermudes D, et al. Tumour-targeting bacteria engineered to fight cancer. Nat Rev Cancer 2018;18:727-43.

10 Junqueira C, Santos LI, Galvão-Filho B, et al. Trypanosoma cruzi as an effective cancer antigen delivery vector. Proc Natl Acad Sci U S A 2011;108:19695-700.

11 Remington JS, Merigan TC. Resistance to virus challenge in mice infected with protozoa or bacteria. Proc Soc Exp Biol Med 1969;131:1184-8.

12 Ruskin J, Remington JS. Immunity and intracellular infection: resistance to bacteria in mice infected with a protozoan. Science 1968;160:72-4.

13 Mahmoud AA, Warren KS, Strickland GT. Acquired resistance to infection with Schistosoma mansoni induced by Toxoplasma gondii. Nature 1976;263:56-7

14 Gentry LO, Remington JS. Resistance against Cryptococcus conferred by intracellular bacteria and protozoa. J Infect Dis 1971;123:22-31.

15 Hibbs JB, Lambert LH, Remington JS. Resistance to murine tumors conferred by chronic infection with intracellular protozoa, Toxoplasma gondii and Besnoitia jellisoni. J Infect Dis 1971:124:587-92.

16 Fox BA, Bzik DJ. De novo pyrimidine biosynthesis is required for virulence of Toxoplasma gondii. Nature 2002;415:926-9.

17 Baird JR, Byrne KT, Lizotte PH, et al. Immune-mediated regression of established B16F10 melanoma by intratumoral injection of attenuated Toxoplasma gondii protects against rechallenge. $J$ Immunol 2013;190:469-78.

18 Baird JR, Fox BA, Sanders KL, et al. Avirulent Toxoplasma gondii generates therapeutic antitumor immunity by reversing immunosuppression in the ovarian cancer microenvironment. $J$ Immunol 2013.

19 Sanders KL, Fox BA, Bzik DJ. Attenuated Toxoplasma gondii stimulates immunity to pancreatic cancer by manipulation of myeloid cell populations. Oncoimmunology 2015.

20 Bjerkås I, Mohn SF, Presthus J. Unidentified cyst-forming sporozoon causing encephalomyelitis and myositis in dogs. $Z$ Parasitenkd 1984;70:271-4.

21 Nam HW, Kang SW, Choi WY. Antibody reaction of human antiToxoplasma gondii positive and negative sera with Neospora caninum antigens. Korean J. Parasitol 1998.

22 Tranas J, Heinzen RA, Weiss LM, et al. Serological evidence of human infection with the protozoan Neospora caninum. Clin. Diagn. Lab. Immunol. 1999;6:765-7.
23 Lobato J, Silva DA, Mineo TW, et al. Detection of immunoglobulin G antibodies to Neospora caninum in humans: high seropositivity rates in patients who are infected by human immunodeficiency virus or have neurological disorders. Clin Vaccine Immunol 2006.

24 Hughes JM, Williams RH, Morley EK, et al. The prevalence of Neospora caninum and co-infection with Toxoplasma gondii by PCR analysis in naturally occurring mammal populations. Parasitology 2006;132:29-36

25 Penarete-Vargas DM, Mévélec MN, Dion S, et al. Protection against lethal Neospora caninum infection in mice induced by heterologous vaccination with a mic1 mic3 knockout Toxoplasma gondii strain. Infect Immun 2010;78:651-60.

26 Dimier-Poisson I, Aline F, Mévélec M-N, et al. Protective mucosal Th2 immune response against Toxoplasma gondii by murine mesenteric lymph node dendritic cells. Infect Immun 2003;71:5254-65.

27 Soldati D, Boothroyd JC. A selector of transcription initiation in the protozoan parasite Toxoplasma gondii. Mol Cell Biol 1995;15:87-93.

28 Coley WB. The treatment of malignant tumors by repeated inoculations of erysipelas. with a report of ten original cases. 1893. Clin Orthop Relat Res 1991;105:487-510.

29 Pan C, Liu H, Robins E, et al. Next-Generation immuno-oncology agents: current momentum shifts in cancer immunotherapy. $J$ Hematol Oncol 2020;13.

30 Yee C. Adoptive T cell therapy: points to consider. Curr Opin Immunol 2018;51:197-203.

31 Forbes NS, Coffin RS, Deng L, et al. White paper on microbial anticancer therapy and prevention. j. immunotherapy cancer 2018;6:78.

32 Breitbach CJ, Paterson JM, Lemay CG, et al. Targeted inflammation during oncolytic virus therapy severely compromises tumor blood flow. Mol Ther 2007;15:1686-93.

33 Jennings VA, Scott GB, Rose AMS, et al. Potentiating oncolytic virus-induced immune-mediated tumor cell killing using histone deacetylase inhibition. Mol Ther 2019;27:1139-52

34 Yang YJ, XZ L, Wang YH, et al. Cd8+ T cell response mediates the therapeutic effects of oncolytic adenovirus in an immunocompetent mouse model. Chin Sci Bull 2012.

35 Kuczynski EA, Vermeulen PB, Pezzella F, et al. Vessel co-option in cancer. Nat Rev Clin Oncol 2019;16:469-93.

36 Channon JY, Seguin RM, Kasper LH. Differential infectivity and division of Toxoplasma gondii in human peripheral blood leukocytes. Infect Immun 2000.

37 W. Tong A, Senzer N, Cerullo V, et al. Oncolytic viruses for induction of anti-tumor immunity. Curr Pharm Biotechnol 2012;13:1750-60.

38 Patel MR, Jacobson BA, Ji Y, et al. Vesicular stomatitis virus expressing interferon- $\beta$ is oncolytic and promotes antitumor immune responses in a syngeneic murine model of non-small cell lung cancer. Oncotarget 2015;6:33165-77.

39 LaRocca CJ, Han J, Gavrikova T, et al. Oncolytic adenovirus expressing interferon alpha in a syngeneic Syrian hamster model for the treatment of pancreatic cancer. Surgery 2015;157:888-98.

40 Bourgeois-Daigneault MC, Roy DG, Falls T, et al. Oncolytic vesicular stomatitis virus expressing interferon-g has enhanced therapeutic activity. Mol Ther Oncolytics 2016.

41 Kowalsky SJ, Liu Z, Feist M, et al. Superagonist IL-15-armed oncolytic virus elicits potent antitumor immunity and therapy that are enhanced with PD-1 blockade. Mol Ther 2018. 